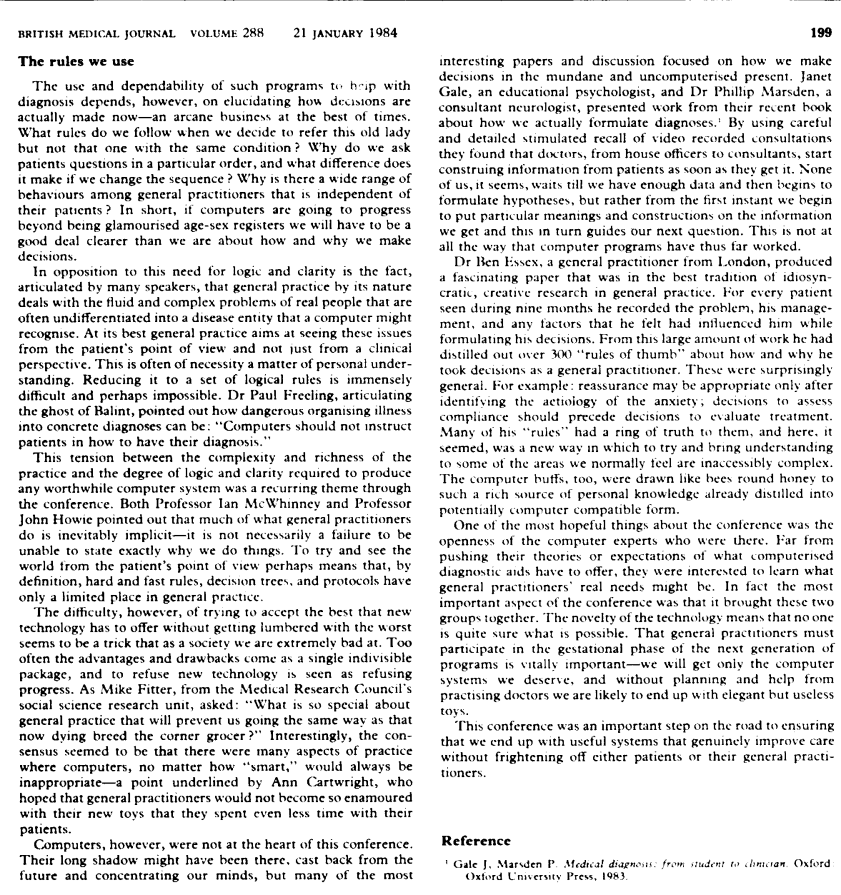

ONE HUNDRED YEARS AGO Hinton's plaster-of-Paris

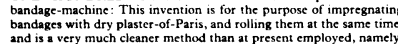

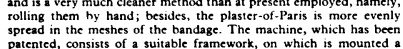

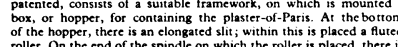

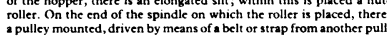

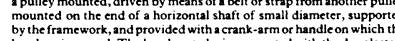
by the framework, and provided with hacrank-arm or handle on which the
bandage is wound. The bandage to be impregrasted with the dry plaster-
of -Paris is passed under the machinc, and brought round the roller at

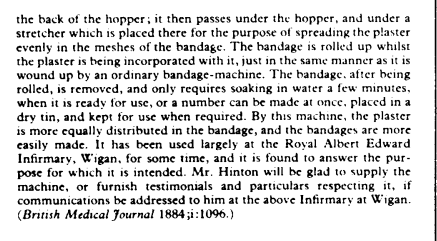

200

BRITISH MEDICAL JOURNAL VOLUME $288 \quad 21$ JANUARY 1984

\section{Practice Research}

\section{Well man clinic in general practice}

G N MARSH, C CHEW

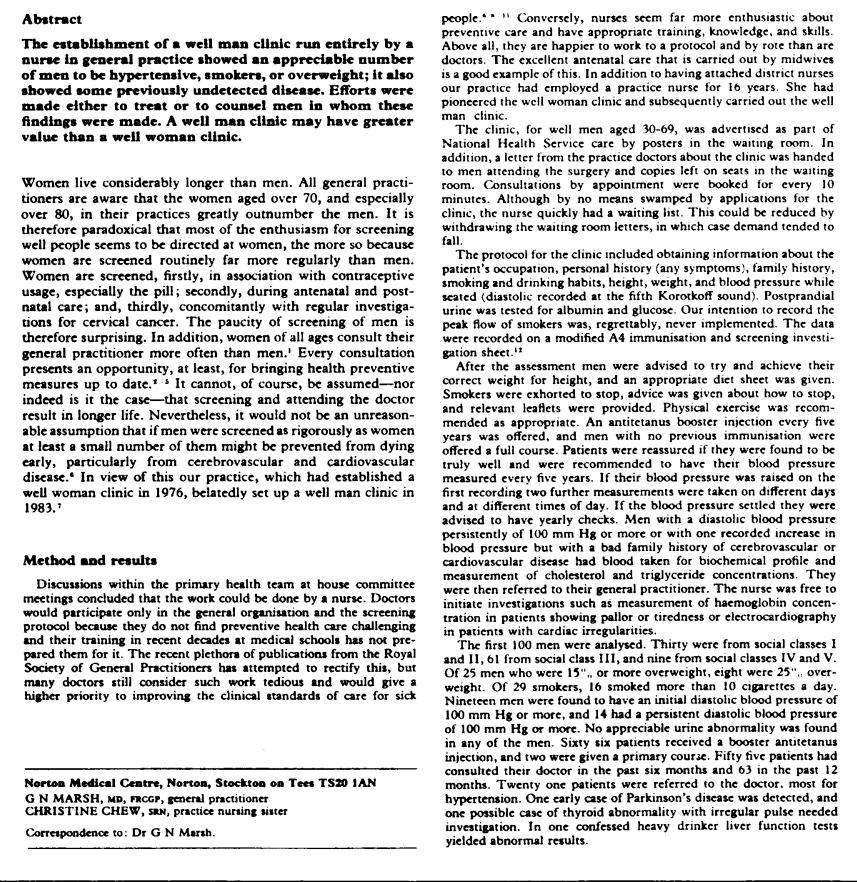

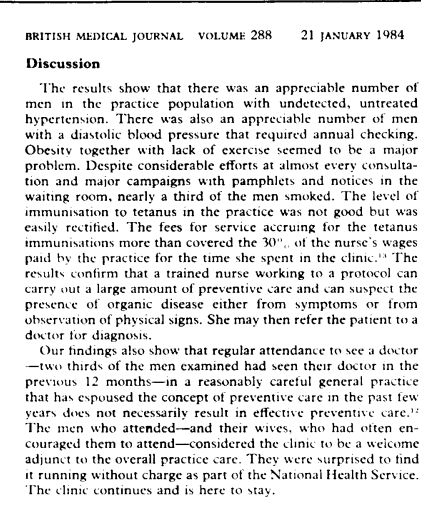

201

References

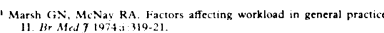

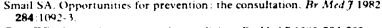

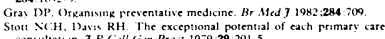

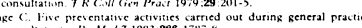

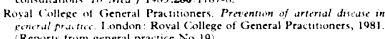

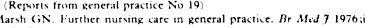

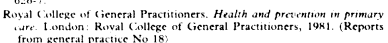

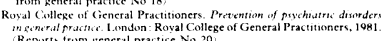

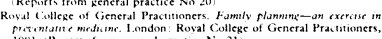

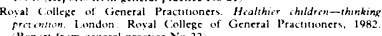

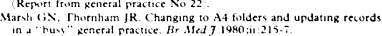

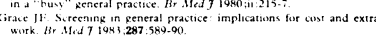

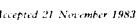

\title{
Medical rehousing
}

E L HOWELLS

Abstract

A local authority and its medical adviser collaborated to
assess the needs of applicants who have special requirements for medical rehousings. Shome characteristsics of the
applicants were examined, together with how successfully applicants were examined, logether with how successfully
their needs were met. Over half the applicants were aped
over 55 . Some three years after their initial applicatio over 55 . Some three years after their initial application
$41 \%$ of of pplicants considered to have medical priority
had been rehoused compared with $36 \%$ of those with no Introduction

Introduction
The adverse effects of substandard housing on health have long

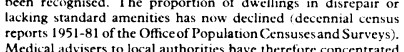
on giving advice on how to meet the needs of thosc whe for
medical reasons have special requirements for trehousing. medical reasons have special requirements for rehousing. I
report here a study of applications for rehousing in Portsmouth,

Community Meddcine Department, Civic Offices, Portsmouth PO E. L. HOWELLLS, MrCM, scnior clinical medical officer

which has a population of 175000 , of whom 104000 live in
owner cecupicd dwellings, 25000 in privately rented accommodation, and 41000 in council owned dwellings.' In addition, the
city onns dwellings housing 60 000 people in a neighbouring
borough Procedures and policies

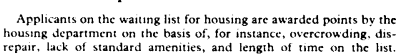

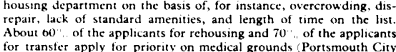

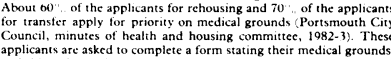

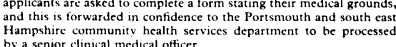

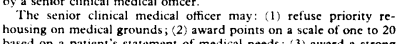

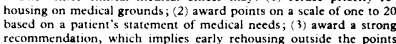

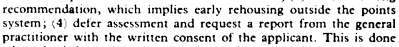

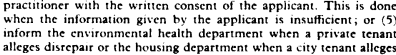

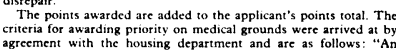

202

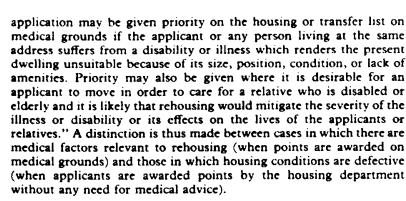
Methods of study and results

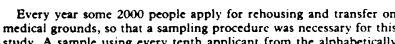

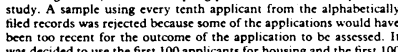

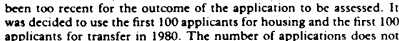

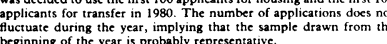

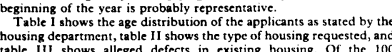

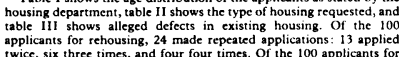
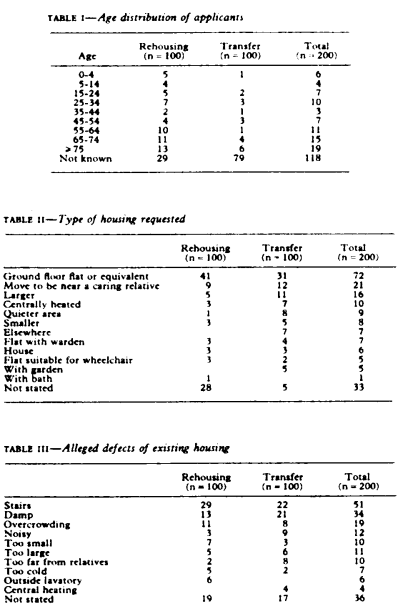

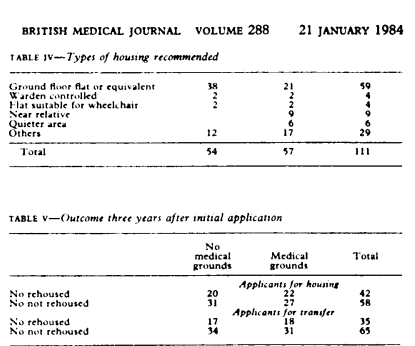

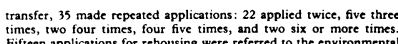

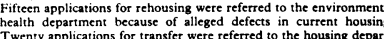

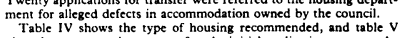

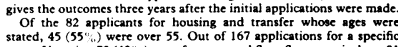

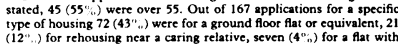

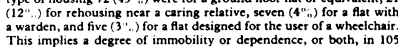

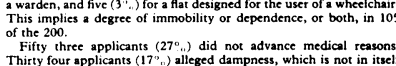

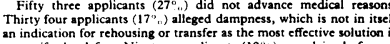

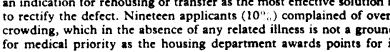

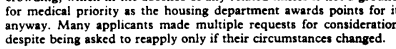
Discusstion

At first sight the system of awarding poins for medical

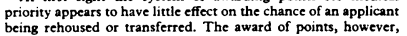

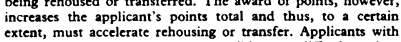
special housing requirements are possibly more difficult to place
than those without. Our experience with he success of rehousing

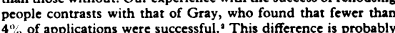

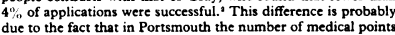

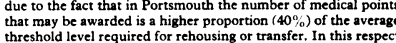
threshold level required for rehousing or transfert In this respect
Porstsouth livs in the middle of the range quoted by thomas

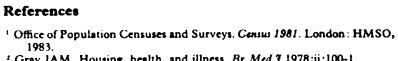

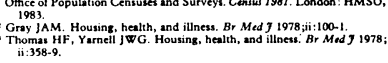
Ascepred 24 Ocabobrir 1985) 